\section{journal of controlled release}

www.elsevier.com/locate/jconrel

\title{
In vitro transfection of HeLa cells with temperature sensitive polycationic copolymers
}

\author{
Mustafa Türk ${ }^{\mathrm{a}}$, Sevil Dinçer ${ }^{\mathrm{a}}$, Işık G. Yuluğ ${ }^{\mathrm{b}}$, Erhan Pişkin ${ }^{\mathrm{a}, *}$

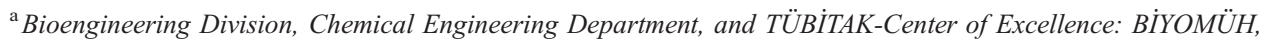 \\ Hacettepe University, Beytepe, Ankara 06530, Turkey \\ ${ }^{\mathrm{b}}$ Department of Molecular Biology and Genetics, Bilkent University, Bilkent, Ankara, Turkey
}

Received 11 August 2003; accepted 15 January 2004

\begin{abstract}
In this study, we investigated different types of polyethyleneimine (PEI) and their block copolymers with $N$ isopropylacrylamide (NIPA) as temperature-sensitive polycationic non-viral vectors for transfection of HeLa cells in cell culture media. First carboxyl-terminated poly(NIPA) was synthesized and then copolymerized with PEIs branched or linear and with two different molecular weights ( 2 and $25 \mathrm{kDa}$ ). Addition of PEI units to the poly(NIPA) chains increased the LCST values up to body temperature. Zeta potentials of the copolymers were significantly lower than the corresponding PEI homopolymers. A green fluorescent protein expressing plasmid was used as a model. Complexes of this plasmid both with PEIs and their copolymers were formed. The zeta potentials of these complexes were between -3.1 and +21.3 . Higher values were observed for the complexes prepared with branched and higher molecular weight PEIs. Copolymerization caused a profound decrease in the positive charges. Particle sizes of the complexes were in the range of $190-1235 \mathrm{~nm}$. Using high polymer/plasmid ratios caused aggregation. The smallest complexes were obtained with the copolymer prepared with branched PEI with $25-\mathrm{kDa}$ molecular weight. Copolymers were able to squeeze plasmid DNA more at the body temperature. Cytotoxicity was observed with PEIs especially with the branched higher molecular weights. Copolymerization reduced the cytotoxicity. The best in vitro DNA uptake efficiency $(70 \%)$ was achieved with the complex prepared with poly(NIPA)/PEI25B. However, poly(NIPA)/ PEI25L was the most successful vector for an effective gene expression without any significant toxicity.
\end{abstract}

(C) 2004 Elsevier B.V. All rights reserved.

Keywords: Gene therapy; Non-viral vectors; Poly(NIPA)/PEI copolymer; In vitro transfection; HeLa cell line

\section{Introduction}

Gene therapy is used to correct or to modulate several diseases, in which genes are combined with a delivery system ("vector") and introduced to the

\footnotetext{
* Corresponding author. Tel.: +90-312-297-7473; fax: +90-312299-2124.

E-mail address: piskin@hacettepe.edu.tr (E. Pişkin).
}

patient to reach target cells to be transfected. One of the most important factors for successful gene therapy is the vector that delivers genes into cells for the production of therapeutic proteins. The development of both viral and non-viral vectors for effectively delivering genes into cells has attracted a great deal of attention in recent years. Viral vectors including adenovirus, adeno-associated virus and retrovirus are still the most widely investigated ones because of their 
high transfection efficiency [1-3]. However, they also have important drawbacks such as issues of safety, immunogenicity, mutagenesis, and the limitation of the amount of genomic information they can carry.

Alternatively, physical methods such as electroporation [4], and non-viral vectors, mainly liposomes and cationic polymers are also used [5-10]. Non-viral gene carriers in clinical gene therapy trails have often used cationic lipids rather than polymeric gene carriers, mainly because of previous experiences $[9,10]$. However, polymeric gene carriers have some advantages over the lipid systems: (i) relatively small size and narrow distribution of complex [11]; (ii) high stability against nuclease; and (iii) easy control of physical factors (e.g., hydrophilicity and charge) by copolymerization.

Recently, water-soluble cationic polymers such as poly(L-lysine) (PLL), polyethyleneimine (PEI) and their block copolymers with polyethylene glycol, have been investigated as alternative non-viral vectors for effective and safe gene delivery [11-14]. Even though cationic polymers and liposomes can carry much larger pieces of DNA compared to viral vectors, they also exhibit some problems such as aggregation of the DNA complexes at physiological conditions and possible toxicity on the target cells due to high surface charge, etc.

The cationic polymers spontaneously form complexes with DNA because of electrostatic interactions between the positively charged amine groups of the polycations and negatively charged phosphate groups of the DNA. These complexes carry extra positive charge on their surfaces, which in turn allows better interaction with the target cell membrane and therefore an enhanced uptake by endocytosis. By endocytosis, the complex goes into the endosome and then moves into the cytoplasm. The complex then translocates from the endosome to the cytoplasm by several mechanisms, such as lipid fusion [15-17] and the proton sponge effect $[18,19]$. The released DNA from the complex moves into the nucleus and the transcription process is initiated. Then the plasmid uptaken in cytoplasm is transcripted by RNA polymerase for the expression of the target protein molecules. Note that there are two important contrary points for the selection of a polycation vector for efficient DNA uptake and gene expression: (i) tight complex formation, which allows a favorable cell uptake and evasion of DNA degradation, and (ii) ease of complex dissociation (which means loose complex formation), favorable for transcription by RNA polymerase [20]. It is almost impossible to fulfill these two opposing phenomena in conventional vectors. In literature, several strategies have been discussed, including using stimuli-responsive or in other words smart polymeric systems as non-viral vectors. This approach is also the main subject of this paper and is discussed in detail below.

PEI, which has become a very popular polycation, allows the condensation of DNA into very small particles which facilitates the endocytosis as well as preventing the DNA from endosomal disruption due to its high protonation capacity (acting as a "proton sponge") [15-23]. The molecular weight and molecular structure of PEI (either branched or linear) are the most effective parameters for the gene transfer activity of this polycation, but the effect of molecular weight is still unclear except for some studies where was observed an increase in gene transfer activity with a decrease in molecular weight. Both branched and linear PEI have been reported to be used successfully to transfect a variety of cells including cell lines and primary cells in vitro and in vivo. Although PEI with a molecular weight of $2 \mathrm{kDa}$ has failed in protein expression, branched PEI with a high MW can be toxic to the cells [22].

In recent years, stimuli-responsive polymers have been promoted as useful tools in diverse applications [24]. The most popular member of these types of polymers is poly ( $N$-isopropylacrylamide) (poly(NIPA) which exhibits a temperature-sensitive character. Copolymerization of NIPA with acrylic acid (AAc) allows the synthesis of both $\mathrm{pH}$ - and temperatureresponsive copolymers [25]. A synthetic cationic copolymer of 2-(dimethylamino) ethyl methacrylate with NIPA has recently been investigated as a thermosensitive gene carrier by Hinrich et al. [26]. Krusawa et al. [27] have also used the same copolymer but include also a third, hydrophobic monomer to control the lower critical temperature (LCST) of the copolymer. Nagasaki [28] synthesized a new cationic L-lysine-modified polyazobenzene dendrimer as a synthetic vector for transfection of mammalian cells, which is the first demonstration of the control of transfection efficiency by light using a synthetic gene vector. 
Recently, we have reported the synthesis and characterization of water-soluble stimuli-responsive polymers, which are block copolymers of poly(NIPA) and PEI, as a smart polycationic DNA carrier for potential use in gene delivery [29]. Here, we present our findings on the DNA uptake and gene expression ability of these copolymers in in vitro cell culture studies.

\section{Materials and methods}

\subsection{Materials}

$N$-isopropylacrylamide (NIPA) was supplied from Aldrich (USA). Branched polyethyleneimine (PEI-B) with two different molecular weights $(25$ and $2 \mathrm{kDa}$, Sigma, USA) and linear polyethyleneimine (PEI-L) (molecular weight: $25 \mathrm{kDa}$, Polysciences, USA) were used to prepare copolymers with poly(NIPA). The water-soluble activating agent, 1 ethyl-3-(3-dimethylamino) propyl carbodiimide (EDAC) was obtained from Sigma (USA). Fluorescein (Aldrich, USA) and SYBR-green I (Sigma) were used for labelling of the copolymers and the plasmid DNA, respectively. Human cervix epithelioid carcinoma cell line (HeLa) was obtained from the tissue culture collection of the Şap Institute (Turkey). Cell culture flasks and other plastic material were purchased from Corning (USA). The growth medium, which is Dulbecco Modified Medium (DMEM) without L-glutamine supplemented fetal calf serum (FCS), and TrypsinEDTA were purchased from Biological Industries (Israel). The plasmid used for transfections was PEGFP-N2 (Clontech, Palo Alta, CA, USA), which carries a strong $\mathrm{CMV}$-immediate early promoter to code for an enhanced green fluorescent protein (GFP). All other reagents used were analytical grade and used as received.

\subsection{Copolymer synthesis and characterization}

Synthesis of carboxyl-ended poly(NIPA) and pol$y($ NIPA)/PEI block copolymers by using a watersoluble carbodiimide (EDAC) has been previously reported [29]. Here, block copolymers carrying either linear or branched PEI with different molecules were synthesized.
FTIR (FTIR 8000, Shimadzu, Japan) and ${ }^{1} \mathrm{H}-\mathrm{NMR}$ (Bruker, AC250, USA) spectroscopies were used to characterize the copolymers, as described before [29].

The viscosities of the polymer solutions prepared in water in the concentration range of $0.25-1.0 \mathrm{~g} / \mathrm{dl}$ were measured with an Ubbelohde automatic viscometer (Schott Gerate, Germany), at constant temperature of $25{ }^{\circ} \mathrm{C}$. The viscosity average molecular weights $\left(M_{\mathrm{v}}\right)$ of polymers were calculated according to the following equation [30].

$$
[\eta]=0.23 \times 10^{-5} M_{\mathrm{v}}^{0.97}
$$

The lower critical solution temperature (LCST) measurements were performed in a spectrophotometer (UV 1602 spectrophotometer, Shimadzu, Japan) equipped with the heating systems and temperature control unit. The temperature of the solutions, containing $1 \%$, w/w polymer, at $\mathrm{pH} 4.0$ (an acetic acid/ acetate buffer) or 7.4 (a phosphate buffer) was increased at a rate of $1{ }^{\circ} \mathrm{C} / \mathrm{min}$ starting from room temperature, and the absorbance of the solution was periodically recorded at a wavelength of $500 \mathrm{~nm}$. The LCSTs, i.e., the temperature at $10 \%$ of maximum absorbance of the polymer solution of the polymers, were calculated from the absorbance-temperature curves [31].

\subsection{Preparation and characterization of the copol- ymer/plasmid complex}

The copolymer stock solution was prepared by dissolving $1 \mathrm{mg}$ copolymer in $1 \mathrm{ml}$ distilled water. And polymer solutions were prepared by dissolving different amounts of copolymer in $0.15 \mathrm{M}, 500 \mu \mathrm{l}$ of $\mathrm{NaCl}$. Twenty-microgram PEGFP-N2 plasmid DNA was dispersed in $500 \mu \mathrm{l}$ of $0.15 \mathrm{M} \mathrm{NaCl}$. These solutions were then mixed and incubated for 15-30 min in order to complete complex formation reactions. Both PEI homopolymers PEI2B, PEI25B and PEI25L and their copolymers with poly(NIPA), namely poly(NIPA)/PEI2B, poly(NIPA)PEI25B, and poly(NIPA)/ PEI25L were included in these studies. Here, B stands for branch and L for linear PEI, and the number at the end gives the molecular weight as $\mathrm{kDa}$. Sizes and zeta potentials of the homo and copolymers, plasmid and copolymer-plasmid DNA complexes were measured at 25 and $37{ }^{\circ} \mathrm{C}$ using a Zetamaster HSA3000 
(Malvern Instrument, France). In order to find the sizes of complexes at $37{ }^{\circ} \mathrm{C}$, we prepared the complexes at $25{ }^{\circ} \mathrm{C}$, warmed up to $37{ }^{\circ} \mathrm{C}$ and then measured the sizes.

For in vitro transfection studies, plasmid solution was obtained by adding $20 \mu \mathrm{g}$ plasmid into $1000 \mu \mathrm{l}$ of $0.15 \mathrm{M} \mathrm{NaCl}$. For complex formation, different amounts of the copolymer solutions $(300-900 \mu \mathrm{l})$ were mixed with $100 \mu \mathrm{l}$ of the plasmid solution. Then, these complex dispersions were used in transfection studies, at which final volume was $2 \mathrm{ml}$.

\subsection{Cytotoxicity}

Twenty-four-well plates containing HeLa cells $\left(80 \times 10^{3}\right.$ cells per well) in DMEM containing no FSC and antibiotics were used. Different amounts of polymers (PEI homo polymers or poly(NIPA)/PEI copolymers) $(4,6.5,9$, and $12 \mu \mathrm{g}$ polymer per $\mathrm{ml})$ were put into the wells containing cells. The plates were kept in the $\mathrm{CO}_{2}$ incubator $\left(37^{\circ} \mathrm{C}\right.$ in $\left.5 \% \mathrm{CO}_{2}\right)$ for $4 \mathrm{~h}$, the medium was replaced with fresh medium, and incubated under the same conditions for $24 \mathrm{~h}$. Following this incubation, HeLa cells were harvested with trypsin-EDTA, and were then dyed with trypan blue. The viable cells were counted with a haemacytometer (C.A. Hausser \& Son Phila, USA).

\subsection{In vitro DNA uptake and gene expression}

A green fluorescent protein expressing plasmid (PEGFP-N2) was amplified to sufficient quantities in Escherichia coli and purified with a Qiagen Midiprep kit (Qiagen, Chartsworth, CA, USA). Then, copolymer-plasmid DNA complexes were prepared as described above (Section 2.3) and 200- $\mu$ l solution in $0.15 \mathrm{M} \mathrm{NaCl}$ was added in each well of the 6-well plates.

For in vitro DNA uptake experiments, a HeLa cell line was used. The growth medium, which is DMEM without glutamine, was supplemented with $10 \%$ fetal calf serum and $10 \mu \mathrm{l} / \mathrm{ml}$ penicillin-streptomycin solution. The following transfection studies were performed. (i) In order to show that the uptake of the copolymers into the cells, the cultured cells were transfected with copolymers or PEI homopolymer. Polymers were labelled with fluorescein before use. (ii) Complexes were used in transfection in this group of studies. Plasmid DNA was first labeled with SYBR-Green I, which intercalated the base pairs of DNA double helix and emitted intense fluorescence light at $520 \mathrm{~nm}$. Then, the complexes were prepared either with copolymers or PEI homopolymers, and used for transfection. (iii) The complexes (not labelled, neither with copolymers nor with the plasmid) were used in the transfection experiments.

For transfection, 6-well plates were used. HeLa cells were placed in the wells $\left(60 \times 10^{3}\right.$ cells per well), and $2 \mathrm{ml}$ of DMEM supplemented with fetal calf serum and antibiotics was added into each well. These wells were then incubated at $37{ }^{\circ} \mathrm{C}$ in $5 \% \mathrm{CO}_{2}$ for $24 \mathrm{~h}$. Afterwards, the medium in each well was replaced with $1.8 \mathrm{ml}$ fresh DMEM (without FCS and antibiotics). The wells were kept in the $\mathrm{CO}_{2}$ incubator $\left(37{ }^{\circ} \mathrm{C}\right.$ in $5 \% \mathrm{CO}_{2}$ ) for $1 \mathrm{~h}$, and then $200 \mu \mathrm{l}$ of the transfection solution (containing copolymers or complexes described above) were placed in each well and left in the incubator at $37{ }^{\circ} \mathrm{C}$ in $5 \% \mathrm{CO}_{2}$ medium for 2-4 h. The media containing complex solutions were then replaced with fresh medium DMEM supplemented with FCS and antibiotics. Transfections were followed by fluorescence microscopy (Fluorescence Inverted Microscope, Olympus IX70, Japan), $4 \mathrm{~h}$ after uptake of copolymer and complex, and $12-120 \mathrm{~h}$ after transfection for GFP expression.

Efficiency of in vitro DNA uptake was calculated as the percentage of the cells having homo- and copolymer/plasmid DNA complex. The cells (both transfected and total) at five different regions (containing about $100-150$ cells in each region) were analyzed and the average values were evaluated. The same approach was used to calculate gene expression efficiency.

\section{Result and discussion}

\subsection{Characterization of copolymers}

\subsubsection{Polymer properties}

FTIR and ${ }^{1} \mathrm{H}-\mathrm{NMR}$ data confirmed the formation of poly(NIPA)/PEI block copolymers which were discussed in detail in our previous paper [29]. Briefly, the following notes were drawn from the FTIR spectra of the homo and copolymers: The amide peaks of NIPA units appeared at $1650-1660 \mathrm{~cm}^{-1}(\mathrm{C}-\mathrm{O}$ 
stretching, amide I), $1535-1540 \mathrm{~cm}^{-1}(\mathrm{~N}-\mathrm{H}$ bending, amide II), and $3420-3550 \mathrm{~cm}^{-1}(\mathrm{~N}-\mathrm{H}$ stretching, amide). $\mathrm{C}-\mathrm{H}$ stretching peaks of isopropyl groups were at $1370-1385$ and $1145-1170 \mathrm{~cm}^{-1}$. In the spectra of the carboxylic acid-ended poly(NIPA), in addition to the characteristic peaks of NIPA component, the characteristic $\mathrm{C}-\mathrm{O}, \mathrm{O}-\mathrm{H}$, and $\mathrm{C}-\mathrm{O}$ stretching bands of carboxylic acid groups appeared at $1710-1765,3358$, and $1260 \mathrm{~cm}^{-1}$, respectively. The intensity of $\mathrm{C}-\mathrm{O}$ stretching band increased relative to the amide I peak of NIPA, when the carboxylic acid groups were included. In the spectrum of poly(NIPA)-PEI copolymer, the peak representing the carboxylic acid groups at $1710-1765 \mathrm{~cm}^{-1}$ disappeared, as expected, due to reaction between the carboxylic end groups of the carboxylic acid-ended poly(NIPA) with the amine groups of PEI. The peak that appeared at $3300-3400 \mathrm{~cm}^{-1}$ also indicated the introduction of the PEI blocks in the copolymer chain. The increase in the intensities of the peaks of $\mathrm{C}-\mathrm{H}$ stretching and bending is probably due to the $\mathrm{CH}_{2}$ and $\mathrm{CH}_{3}$ groups coming from PEI.

The important points observed on the ${ }^{1} \mathrm{H}-\mathrm{NMR}$ spectra of the homo- and copolymers were as follows: The only difference in the spectra of the poly(NIPA) and carboxylic acid-ended poly(NIPA) was the signal observed at $11.4-13.8 \mathrm{ppm}$, which belongs to the proton of the carboxylic acid. In the spectrum of the poly(NIPA)-PEI copolymer, there was no peak at 11.4-13.8 ppm, which indicated the loss of the carboxylic acid groups as a result of the reaction between poly(NIPA) and PEI. The protons coming from the PEI were not observed separately because of the overlapping of the similar protons of poly(NIPA).

The viscosity average molecular weight of the copolymers determined by viscosimetry in water at $25{ }^{\circ} \mathrm{C}$ are given in Table 1 .

\subsubsection{Temperature sensitivity}

Here, we investigated stimuli-responsive behavior of both the carboxylic acid-ended poly(NIPA) and

Table 1

Viscosity average molecular weights of copolymers

\begin{tabular}{ll}
\hline Polymer & $M_{\mathrm{v}}$ \\
\hline Poly(NIPA)/PEI2B & 14,670 \\
Poly(NIPA)/PEI25L & 53,100 \\
Poly(NIPA)/PEI25B & 55,200 \\
\hline
\end{tabular}

Table 2

LCST values of homo and copolymers at $\mathrm{pH}: 7.4$

\begin{tabular}{ll}
\hline Polymer & LCST value $\left({ }^{\circ} \mathrm{C}\right)$ \\
\hline Poly(NIPA) & $31.0 \pm 1.0$ \\
Poly(NIPA)/PEI2B & $35.5 \pm 1.5$ \\
Poly(NIPA)/PEI25L & $36.6 \pm 2.1$ \\
Poly(NIPA)/PEI25B & $39.6 \pm 2.0$ \\
\hline
\end{tabular}

three different block copolymers synthesized here by observing the changes in the absorbance of the solutions at $500 \mathrm{~nm}$ depending on the temperature, as described previously. As a general tendency, the absorbance increased with increasing temperature and the transparent polymer solution became turbid. Note that all transitions were thermally reversible so that the turbid copolymer solutions at the temperatures higher than LCST again turned into the transparent form when the temperature was decreased below LCST.

Copolymerization of poly(NIPA) with more hydrophilic PEI chains caused significant increases in the LCST of the poly(NIPA) chains, as expected (Table 2 and Fig. 1). A similar trend with the copolymer of NIPA and DMAEMA in which DMAEMA acts as a hydrophilic comonomer was also observed by others [26]. The increase in the LCST was more in the

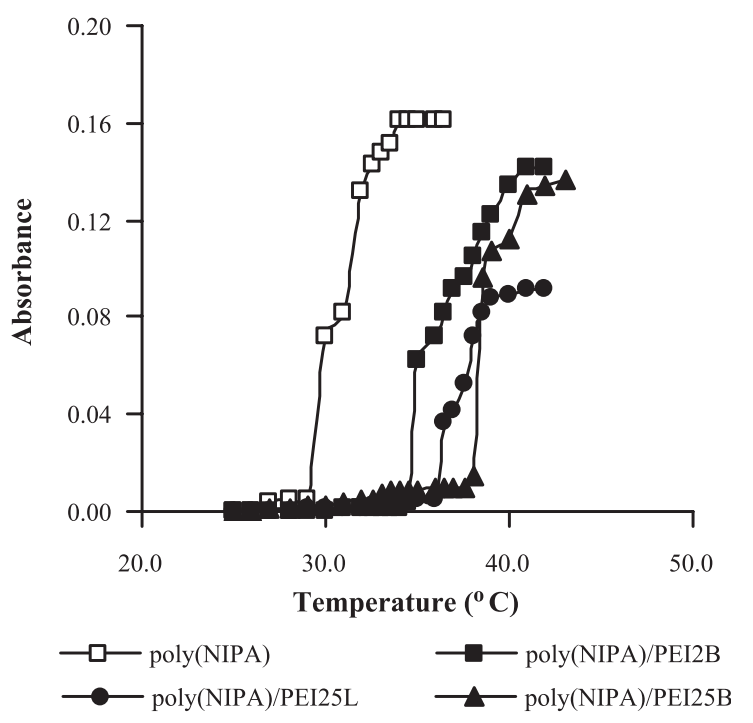

Fig. 1. Temperature dependence of poly(NIPA) and its copolymers with different PEIs at $\mathrm{pH}$ 7.4. 
copolymer prepared with the branched PEI comparing to the linear PEI with the same molecular weight. Note that branched PEI contains much more primary amine groups (each branch has one amino end-group) which resulted more hydrophilic chains and therefore a higher LCST value. Due to the same reason, using PEI with higher molecular weight ( $25 \mathrm{kDa}$ branched) caused more increase in the LCST of the copolymer.

\subsubsection{Zeta potentials}

Zeta potentials of plasmid DNA, homo and copolymers at $37{ }^{\circ} \mathrm{C}$ are given in Table 3. As seen here, the plasmid DNA was negatively charged while all other homo and copolymers were positively charged. Zeta potential was increased with both an increase in the chain length and also with branching, as expected. Copolymerization of PEIs with NIPA caused observable decreases in the zeta potential values.

\subsection{Characterization of copolymer-plasmid DNA complexes}

Polycations are one of the most important groups of non-viral vectors used for transfection in gene therapy [32]. Due to their positive charges at physiological conditions, they interact with the negatively charged plasmid DNA and form complexes with different charges and sizes. The two important properties of these complexes are high transfection yields but damaging (toxic) side effects due to the charge.

In this part of the study, we measured the zeta potentials and particle sizes of the complexes prepared with different homo PEIs and poly(NIPA)/PEI copolymers. We also changed the polymer/plasmid DNA ratio to optimize the amount of polymer to be used for

Table 3

Zeta potentials of plasmid DNA and homo and copolymers at $37^{\circ} \mathrm{C}$

\begin{tabular}{lc}
\hline Sample & Zeta potential $(\mathrm{mV})^{*}$ \\
\hline Plasmid DNA & -21 \\
PEI2B & +3.7 \\
PEI25L & +38 \\
PEI25B & +46 \\
Poly(NIPA)/PEI2B & +3 \\
Poly(NIPA)/PEI25L & +30 \\
Poly(NIPA)/PEI25B & +28 \\
\hline
\end{tabular}

* Average values are given here. Standard deviations were less than $\pm 3 \mathrm{mV}$. the unit amount of plasmid DNA molecules for complex formation. The particle sizes of the complexes were measured at two different temperatures, 25 and $37{ }^{\circ} \mathrm{C}$ in the case of copolymers used for complex formation to see the squeezing effect of the temperature sensitive poly(NIPA) blocks on the copolymer chains. Note that all copolymers were at the extended state at $25{ }^{\circ} \mathrm{C}$ (much lower than the LCST values), and therefore can easily form condensates with plasmid. However, they formed globular structures at $37{ }^{\circ} \mathrm{C}$ (above or close to their LCST values), which squeeze the plasmid to smaller size.

\subsubsection{Zeta potentials}

Different values for zeta potentials for plasmid complexes prepared with different polymers have been reported in the relevant articles. Hinrich et al. have measured the zeta potentials of complexes of plasmid DNA and poly(DMAEMA-co-NIPA) copolymers and reported that the zeta potentials increased with increasing copolymer/plasmid ratio until a maximum value is reached after which it remained constant around a copolymer/plasmid ratio of 8 . The zeta potentials of the complexes prepared with copolymers with different comonomer ratios were between +10 and $+20 \mathrm{mV}$ (the plateau values), and were independent of the molecular weight of the copolymer [26]. Kirchler et al. [33] reported that PEI/DNA complexes had a zeta potential between +30 and $+35 \mathrm{mV}$ at the $\mathrm{N} / \mathrm{P}$ ratios usually used for complete complexation (e.g., N/P $>4$ ). They argued that there seemed to be no differences in zeta potential between DNA complexes using different PEIs. Erbacher et al. [34] reported that grafting neutral hydrophilic molecules, such as carbohydrates, to PEI should increase the solubility of complexes and prevent their aggregation. The size and charge of glycosylated PEI/DNA complexes were controlled by their N/P ratio, by the length of saccharide, and by the extent of grafting. Increasing the amount of grafted maltose led to a progressive reduction of particle surface charge, the largest effect being obtained at high N/P ratios. The zeta potentials of their PEI25-maltose/DNA and PEI25-dextran/DNA complexes were between -20 and $+20 \mathrm{mV}$. Positive values were observed only when the $\mathrm{N} / \mathrm{P}$ ratio was higher than 5. Ahn et al. [35] reported that complete neutralization was around a polymer/plasmid ratio of 0.8 for PEI/PEG and plasmid complexes and the 
zeta potential reached a plateau value $(+40 \mathrm{mV})$ at a ratio of around 2. Tang and Szoka [36] have studied several polycationic vectors and reported that positively charged complexes of these vectors with DNA do not cluster, because of strong electrostatic repulsion in which zeta potentials are larger than $+15 \mathrm{mV}$.

Table 4 gives the zeta potentials of the complexes. By comparing the data given in Tables 3 and 4, the following important results can be concluded: The zeta potential of free plasmid was found to be around $-21 \mathrm{mV}$, which goes to positive values after complex formation with PEI homopolymers or poly(NIPA)/PEI copolymers, except when low molecular weight PEI $(2 \mathrm{kDa})$ is used. Even in that case, positive values were observed when the polymer/ plasmid DNA ratio is high (6 or 9). The complexes prepared with higher molecular weight PEIs (PEI25L and PEI25B) exhibited higher positive charges. This is more pronounced in the case of branched PEI (PEI25B). Again, incorporation of NIPA comonomer in the polymer chains resulted in complexes with lower zeta potentials compared to those prepared with homo PEIs. Increase in the polymer/plasmid ratio also caused significant increases in the positive charges of the complexes prepared both with homo and copolymers. These are all expected results as the positive charge of the complexes depends on the positive charge of the polymer used. When we increase the chain length of PEI and use branched ones, homo PEI and more polymer for one unit of plasmid DNA we can have complexes with higher zeta potentials.

Table 4

Zeta potentials of the complexes prepared with homo PEIs and copolymers by using three different polymer/plasmid DNA ratios (v/w) at $37^{\circ} \mathrm{C}$

\begin{tabular}{lrcr}
\hline Complex & \multicolumn{3}{c}{ Zeta Potential $(\mathrm{mV})^{*}$} \\
\cline { 2 - 5 } Polymer/plasmid DNA ratio $\longrightarrow$ & 3 & 6 & \multicolumn{1}{c}{9} \\
\hline PEI2B/Plasmid DNA & +2.1 & +0.8 & +1.8 \\
PEI25L/Plasmid DNA & +9.8 & +13.0 & +15.4 \\
PEI25B/Plasmid DNA & +15.2 & +19 & +21.3 \\
Poly(NIPA)/PEI2B/Plasmid DNA & -3.1 & -0.7 & +0.9 \\
Poly(NIPA)/PEI25L/Plasmid DNA & +7.6 & +10.0 & +12.8 \\
Poly(NIPA)/PEI25B/Plasmid DNA & +11.7 & +14.1 & +16.5 \\
\hline
\end{tabular}

*Average values are given here and standard deviations were in the range of \pm 0.3 and $2 \mathrm{mV}$.

\subsubsection{Particle sizes}

As discussed in the related literature, one of the important properties of polycation-plasmid DNA complexes is their size for effective transfection [33]. Positively charged polycations are complexed with the negatively charged plasmid DNA and form complexes even smaller than $100 \mathrm{~nm}$ compared to the plasmids with much larger sizes (even more than 1000 $\mathrm{nm}$ ). The shrinkage (or condensation) is important because it brings the large size plasmid molecules to much lower sizes that can easily enter the cells efficiently.

However, there are still contrary discussions about the optimum size of the complexes to achieve high transfection yields.

Several groups have studied the sizes of plasmid complexes prepared with different polycations. When formed at low salt concentrations and dilute DNA concentrations, PEI/DNA complexes have been found to form toroid structures of $40-60$ [36] to $50-80 \mathrm{~nm}$ [37] by dynamic light scattering or even $20-40 \mathrm{~nm}$ by AFM [38]. Wightman et al. [39] studied complexation and aggregation of both linear and branched PEIs with plasmid DNA in salt-free medium. Size of the complexes prepared with linear PEI was around $121 \mathrm{~nm}$, while the size of the branched PEIs was about 200 $\mathrm{nm}$. Erbacher et al. [34] reported that the size and morphology of glycoslated PEI/DNA complexes were controlled by their N/P ratio, by the length of saccharide, and by the extent of grafting. Hinrich et al. [26] reported that the size of poly(DMAEMA-co-NIPA)/ plasmid complexes was $200 \mathrm{~nm}$, and increased in proportion to the NIPA content of the copolymer. The complexes using high-molecular-weight poly (DMAEMA-co-NIPA) or lower ratios of NIPA with plasmid were relatively stable at $37{ }^{\circ} \mathrm{C}$, when compared to the other fractions of copolymer. Jeong et al. estimated that the complex formation of PEI50L with plasmid DNA nanoparticles around 200-nm size occurred above the N/P ratio of 25 . Highly compacted form of the complex $(150 \mathrm{~nm})$ appeared between the N/P ratio of 60 and 80 . Larger particles $(>1500 \mathrm{~nm})$ were generated at the N/P ratio of 5.0, at which surface zeta potential value of the complex particles became near 0 . They assumed that the increased size of complex at the N/P ratio of 5 was clearly due to aggregation between complexes having almost neutral charge [40]. Ahn et al. [35] reported that after the 
complete neutralization around the polymer/plasmid ratio of 0.8 , particle sizes ranged from $129.8 \pm 0.9$ to $151.8 \pm 3.4 \mathrm{~nm}$ and mentioned that the apparent size of complex prepared from the PEI/PEG copolymer is still in the range suitable for an efficient entry into the cells.

Table 5 gives the average sizes of the complexes prepared in this study with three different homo PEIs and three copolymers of poly(NIPA) at room temperature at an ionic strength of 0.15 . Note that we also prepared complexes with the same homo or copolymers by changing the polymer/plasmid ratio (three different ratios: 3, 6, 9). Particle size measurements for the copolymer-plasmid complexes were carried out at two different temperatures $25{ }^{\circ} \mathrm{C}$ (room temperature, a temperature lower than their LCST values) and $37{ }^{\circ} \mathrm{C}$ (body temperature, a temperature around the LCST values of the copolymers).

Note that the size measurements were performed by using a Zeta Sizer which gives a size distribution curves (a gaussian type curve). The maximum value is the average size and the distance between the two ends at the base is reflected in the standard deviations (the equipment software does the evaluations and gives these values automatically). The size distribution curves were almost symmetrical to the vertical line passing through the maximum, in all cases. Almost $90 \%$ of the particles have particle sizes around the maximum, and there were about $5 \%$ very large and $5 \%$ very small particles. The size distribution is expected because the aqueous phase contains polymer/plasmid condensates plus most probably the unconjugated polymer and plasmid DNA. Note that, as usual, the polymers used are all mixtures of polymer chains with different sizes (molecular size distribution). Therefore, the condensates may most probably be formed from more than one polymer for one plasmid, or even contain more than one plasmid (as also speculated in the related literature) as aggregates. However all these are very speculative, and it is impossible to make the condensate size distribution very narrow. It is also very difficult to separate the small and large ones practically. Therefore, we preferred to use the whole mixture in the transfection studies and submit the size distribution data as it is.

The following important notes can be drawn from Table 4: Note that the size of the plasmid DNA we have used was about $740 \mathrm{~nm}$. When we used PEI with lower molecular weight (PEI2B) the size of the complex was larger than the plasmid itself, especially in the case of complexes prepared with homo PEI2B and at the higher polymer/plasmid DNA ratios. In these cases, most probably, a number of polymer chains were accumulated around the plasmid and caused formation of some kind of aggregates. However, when both the homo and copolymers of PEI with larger molecular weights (PEIs with $25 \mathrm{kDa}$ molecular weight) either linear (L) or branched (B) were used, the plasmid DNA was condensed (squeezed) after complex formation, except in the case of a polymer/ plasmid ratio of 9 . In this latter case, there were most probably also some aggregations. The size of the complexes decreased to an average value of $190 \mathrm{~nm}$ when the poly(NIPA)/PEI25B copolymer was used for complex formation. As a general trend, complexes prepared with branched PEIs were smaller than those prepared with the linear ones. This was most probably due to more positive charge groups on the branched

Table 5

Particle sizes (mean \pm standard deviation) of the complexes prepared with homo PEIs and copolymers by using three different polymer/plasmid DNA ratios (v/w) at 25 and $37^{\circ} \mathrm{C}$

\begin{tabular}{|c|c|c|c|c|c|c|}
\hline \multirow{3}{*}{$\begin{array}{l}\text { Complex } \\
\text { Polymer/plasmid DNA ratio } \longrightarrow \\
\text { Temperature } \longrightarrow\end{array}$} & \multicolumn{6}{|c|}{ Average particle size (nm) } \\
\hline & \multicolumn{2}{|c|}{3} & \multicolumn{2}{|l|}{6} & \multicolumn{2}{|l|}{9} \\
\hline & at $25^{\circ} \mathrm{C}$ & at $37^{\circ} \mathrm{C}$ & at $25^{\circ} \mathrm{C}$ & at $37^{\circ} \mathrm{C}$ & at $25^{\circ} \mathrm{C}$ & at $37^{\circ} \mathrm{C}$ \\
\hline PEI2B/plasmid DNA & $830 \pm 85$ & $836 \pm 80$ & $985 \pm 125$ & $992 \pm 140$ & $1228 \pm 85$ & $1235 \pm 100$ \\
\hline PEI25L/plasmid DNA & $432 \pm 65$ & $430 \pm 80$ & $548 \pm 44$ & $543 \pm 40$ & $1165 \pm 120$ & $1180 \pm 100$ \\
\hline PEI25B/plasmid DNA & $255 \pm 35$ & $260 \pm 40$ & $350 \pm 50$ & $345 \pm 40$ & $1100 \pm 80$ & $1080 \pm 100$ \\
\hline Poly(NIPA)/PEI2B/plasmid DNA & $760 \pm 80$ & $723 \pm 40$ & $743 \pm 100$ & $714 \pm 120$ & $1123 \pm 100$ & $1114 \pm 100$ \\
\hline Poly(NIPA)/PEI25L/plasmid DNA & $385 \pm 80$ & $360 \pm 100$ & $350 \pm 80$ & $305 \pm 80$ & $1154 \pm 200$ & $1030 \pm 200$ \\
\hline Poly(NIPA)/PEI25B/plasmid DNA & $280 \pm 80$ & $260 \pm 80$ & $253 \pm 40$ & $190 \pm 40$ & $1034 \pm 180$ & $950 \pm 200$ \\
\hline
\end{tabular}


PEI chains. Another important observation is the effect of temperature on complex size. This is actually one of the originalities of this study, which is using a temperature sensitive copolymer (due to poly(NIPA) blocks on the polymer chain) for complex formation instead of PEI homopolymers. The size of the complexes were smaller at $37{ }^{\circ} \mathrm{C}$ than those observed at $25{ }^{\circ} \mathrm{C}$ for these copolymers due to the squeezing effect of the copolymer around or over its LCST value. It should be noted that the size distribution curve shifted significantly when we change the temperature from 25 to $37{ }^{\circ} \mathrm{C}$, especially for the condensates prepared with using temperature responsive copolymers of linear and branched PEI with an average molecular weight of $25,000 \mathrm{Da}$, with a polymer/plasmid ratio of 6 . Comparing to these data, the size changes in the condensates prepared with homo PEIs were not significant.

\subsection{In vitro cytotoxicity}

Cytotoxicity of the vectors used in gene therapy is an important consideration. Several groups have investigated the in vitro cytotoxicity of their vectors. Jeong et al. investigated the influence of cationic charge densities and molecular weights of the PEIs on cell viability by monitoring with MTT-assay. PEI25B, which had the highest positive charge density in its backbone among the polymers used, showed the greatest cytotoxicity compared to its linear counterparts. As the cationic charge density in the polymer backbone of the PEILs increased, cell viabilities were progressively lowered. They concluded that the charge density as well as the molecular weight of the PEI50L could be an important factor for cell viability [40]. Fischer et al. [41-43] have studied effects of molecular weight and the type of PEIs on cytotoxicity with the MTT-assay. They have concluded the following points: The cytotoxicity and uptake of PEI is affected by polymer size and structure. High cationic charge densities, a compact and highly branched structure as well as high molecular weights affect the biocompatibility in a negative sense. PEI800B binding caused massive necrosis while PEIs with lower molecular weights (PEIB1.8, PEIB2 or PEIB11) and linear PEI25L showed acceptable cytotoxicity profiles concentrations. Similar observations were reported for poly-L-lysine [44]. Hinrich et al. [26] found that the cytotoxicity of poly(DMAEMA-co-NIPA)/plasmid decreased with an increase in the concentration of NIPA.

In this study, we also investigated the cytotoxicity of both PEI homopolymers and corresponding poly (NIPA)/PEI copolymers that we used for transfection. Fig. 2 gives the number of viable cells in each group after incubation of the cells with polymers (with different amounts) for $24 \mathrm{~h}$ in cell culture media (see also Table 6). Note that wells containing cells but no polymer were also studied as positive control.

The following important results can be drawn from this graph: The low molecular weight PEI (PEI2B) and its copolymer with NIPA (poly(NIPA)/PEI2B) did not cause any observable toxicity in the range of polymer concentration that we have used in this study. The toxicity of PEIs with higher molecular weight (25 $\mathrm{kDa}$ ) was significant, especially for the branched one (PEI25B), most probably due to higher positive charge on the polymer chains (much higher in the case of PEI25B). The increase in the amount of polymer added in each well caused more toxicity (more dead cells), as expected. It is important to note that using copolymer instead of PEI homopolymers reduced the cytotoxicity profoundly, and this was actually one of the main targets of this study when it was initiated. This may be due to incorporation of NIPA in the copolymer which reduced the charge density on each polymer chain. In addition, most

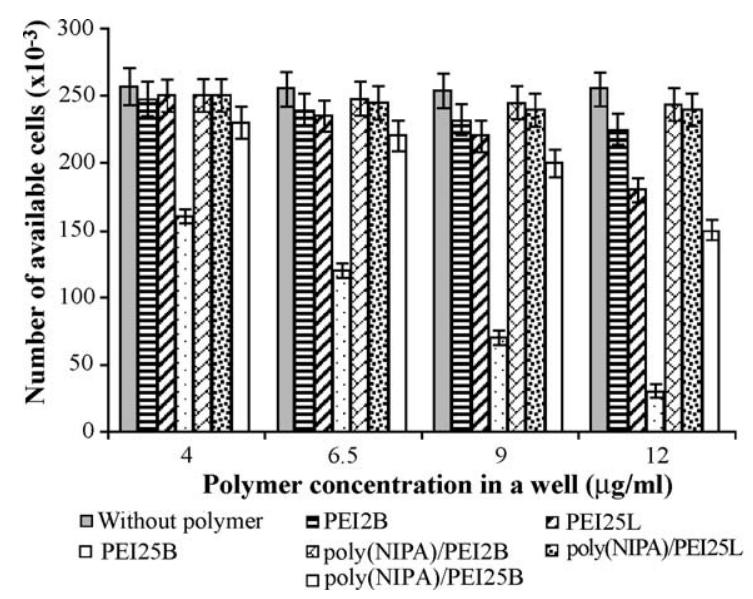

Fig. 2. In vitro cytotoxicity (HeLa cell line) of PEI homopolymers and poly(NIPA)/PEI copolymers. The blocks show the average numbers and the bars give the standard deviations. 
Table 6

Experimental data for in vitro cytotoxicity (HeLa cell line) of PEI homopolymers and poly(NIPA)/PEI copolymers

\begin{tabular}{llllllll}
\hline \multicolumn{2}{l}{ Number of viable cells $\left(\times 10^{-3}\right)$} \\
$\begin{array}{l}\text { Polymer amount in } \\
\text { a well }(\mu \mathrm{g} / \mathrm{ml})\end{array}$ & $\begin{array}{l}\text { Without } \\
\text { polymer }\end{array}$ & PEI2B & PEI25L & PEI25B & $\begin{array}{l}\text { Poly(NIPA)/ } \\
\text { PEI2B }\end{array}$ & $\begin{array}{l}\text { Poly(NIPA)/ } \\
\text { PEI25L }\end{array}$ & $\begin{array}{l}\text { Poly(NIPA)/ } \\
\text { PEI25B }\end{array}$ \\
\hline 4 & $257 \pm 5$ & $248 \pm 5$ & $250 \pm 5$ & $160 \pm 4$ & $250 \pm 5$ & $250 \pm 5$ & $230 \pm 5$ \\
6.5 & $255 \pm 5$ & $240 \pm 5$ & $235 \pm 5$ & $120 \pm 3$ & $248 \pm 5$ & $245 \pm 5$ & $220 \pm 5$ \\
9 & $254 \pm 5$ & $232 \pm 5$ & $220 \pm 5$ & $70 \pm 3$ & $245 \pm 5$ & $240 \pm 5$ & $200 \pm 5$ \\
12 & $255 \pm 5$ & $225 \pm 4$ & $180 \pm 4$ & $30 \pm 3$ & $243 \pm 5$ & $238 \pm 5$ & $150 \pm 5$ \\
\hline
\end{tabular}

probably the globular form of these temperature sensitive copolymers at body temperature made the total copolymer chain less cytotoxic.

\subsection{In vitro DNA uptake and gene expression studies}

For successful gene therapy, efficient and safe vectors are essential because they deliver genes to target cells and aid gene expression of therapeutic peptides. Much research and development is being applied to obtaining better vectors of both viral and non-viral types. At present, this research is mainly directed to obtaining higher transfection efficiency of genes and increased safety of vector systems.

Godbey et al. examined transfection efficiencies of complexes prepared with different PEIs and with various $\mathrm{N} / \mathrm{P}$ ratios. They reported that transfection levels increased up to $1.8 \mu \mathrm{g} \mathrm{PEI} / \mu \mathrm{g}$ plasmid $(\mathrm{N} /$ $\mathrm{P}=13.33$ ). Lower ratios were less efficient, whereas at higher ratios $(\mathrm{N} / \mathrm{P}=20)$ a significant decrease in transfection efficiency was observed most likely due to a cytopathic effect [23].

Wightman et al. compared gene transfer properties of linear and branched PEI25 and found a higher efficiency of linear PEI25. When in vitro transfection with linear PEI and labeled DNA is carried out, DNA particles are seen not only in the cytoplasm but even passing into the nucleus, whereas complexes with branched PEI are visible only in the cytoplasm [45].

Jeong et al. estimated that the branched PEI of lower molecular weight $(50 \mathrm{~K})$ provided better transfection efficiency than those of higher molecular weight (200K) due to the molecular weight-dependent cytotoxicity [40]. Since the N/P ratios of the polymer/ DNA complexes were kept constant at 20, they implied that the total amount of cationic charge did not seem to be a major factor. In contrast, the charge density and molecular weight of the PEIL played a more critical role in cell transfection. They claimed that the highest transfection efficiency could be obtained at the N/P ratio of 25 , at which the PEIL showed similar transfection efficiency to that of branched PEI. Interestingly, an equivalent level of transfection was still maintained with increasing the $\mathrm{N} / \mathrm{P}$ ratio.

Ahn et al. performed a gene expression study of PEI/PEG copolymer with different charge ratios between $6 / 1$ and $14 / 1$ to plasmid DNA and PEI with molecular weight of 1800 , which is the same molecular weight of initial PEI used for the synthesis of copolymers, as a control [35]. As expected from an increased molecular weight of the copolymer, the transfection efficiency increased with the charge ratio of copolymer/plasmid up to three times higher than that of PEI with the initial molecular weight. Although the increase by three times of the efficiency of PEI1.8 was still not comparable to the high transfection efficiency of PEI25, the results from the copolymers in this study have opened up a possibility of improving the transfection efficiency with reduced toxicity of PEI.

Ogris et al. [37] have estimated the transfection efficiency of branched PEI800/DNA complexes in vitro and in vivo and found that the small particles had a significantly lower transfection efficiency than larger ones.

Kirchler et al. [33] explained this by stating that osmolytic endosomal release by the 'proton sponge' mechanism might work more efficiently when the endosomes are filled with larger PEI/DNA complexes compared to a similar number of small particles. For linear PEI22 complexes, a high transfection efficacy, particularly in vivo, was found when the complexes were formed at 5\% glucose, which gives small complexes. In Kirchler et al.'s recent study indicated that, compared to the rather stably condensed DNA com- 
plexes formed with branched PEIs, complexes with linear PEI seem to have lower stability, which allows the initially small complexes formed at low ionic strength, to grow as soon as they are transferred into a medium of physiological ionic strength.

Homogenous and small size of PEI/DNA complex has been shown to produce a high level of gene expression in mature mouse brain by Lemkine et al. [46]. The optimal transfection efficiency was found at a pDMAEMA/DNA ratio of $3: 1(\mathrm{w} / \mathrm{w})$, a ratio at which homogenous complexes $150 \mathrm{~nm}$ in diameter could be formed. Interestingly, the transfection efficiency of the complexes was not affected by the presence of serum proteins, even though the presence of serum is known to adversely affect transfection efficiency in other cases.

Hinrich et al. [26] evaluated transfection efficiencies of DMAEMA and NIPA temperature-sensitive copolymers and stressed the following points: The number of transfected cells increased with increasing polymer concentration until a maximum was reached at a polymer/plasmid ratio of 2-4 after which it decreased, and they ascribed this decrease to the increase a cytotoxicity caused by the presence of an increasing amount of polymer. The maximum transfection efficiency strongly decreased with increasing NIPA content of the copolymer. Transfection efficiencies of complexes with copolymers were lower compared to those with polyDMAEMA homopolymer.

Kurisawa et al. [27] prepared a thermosensitive terpolymer, poly(NIPA)-co-DMAEMA-co-butylmetacrylate, and evaluated its transfection efficiency at different incubation temperatures. They stated that BMA is the hydrophobic component, and thus the solubility of terpolymer/plasmid DNA complexes is probably regulated by both ionic and hydrophobic interactions. The terpolymer was insoluble above 21 ${ }^{\circ} \mathrm{C}$ and soluble below $21{ }^{\circ} \mathrm{C}$ since its LCST was that temperature. The terpolymer/DNA complexes showed partial dissociation at $20{ }^{\circ} \mathrm{C}$ but no dissociation at 37 ${ }^{\circ} \mathrm{C}$, suggesting that the formation/dissociation of the complex was also modulated by temperature. Transfection efficiency of polyDMAEMA/plasmid DNA incubated at $37{ }^{\circ} \mathrm{C}$ for $48 \mathrm{~h}$ was higher than if the complex was incubated at either $20^{\circ} \mathrm{C}$ for $3 \mathrm{~h}$ or at 37 ${ }^{\circ} \mathrm{C}$ for $45 \mathrm{~h}$. However, the transfection efficiencies of terpolymer/DNA complexes incubated at $20{ }^{\circ} \mathrm{C}$ for 3 $\mathrm{h}$ and $37^{\circ} \mathrm{C}$ for $45 \mathrm{~h}$ were much higher than for those incubated at $37{ }^{\circ} \mathrm{C}$ for $48 \mathrm{~h}$. The increase in transfection when the temperature was lowered was due to the formation/dissociation control of the thermosensitive polymer. Terpolymer/DNA complexes could easily be dissociated for transcription below the LCST, while above the LCST these complexes were tightly formed by additional hydrophobic interaction due to thermoresponsive copolymer aggregation.

\subsection{Our studies}

We investigated both the in vitro DNA uptake and gene expression of HeLa cells in cell culture medium using PEI homopolymers (PEI2B, PEI25L, PEI25B) and poly(NIPA)/PEI copolymers (poly(NIPA)/PEI2B, poly(NIPA)/PEI 25L, poly(NIPA)/PEI25B) as nonviral vectors.

In the preliminary studies, in order to obtain the optimal medium for transfection studies, we used polymers in different solutions including pure water, PBS, $0.15 \mathrm{M} \mathrm{NaCl}, 20 \mathrm{mM}$ HEPES, and 5\% glucose. Low uptake and no gene expression were achieved with all solutions except in $0.15 \mathrm{M} \mathrm{NaCl}$, therefore we used this solution in the rest of the studies. After conducting the experiments in medium at different $\mathrm{pH}$ values, we decided to carry out at $\mathrm{pH}$ : 7.4, the value at which the highest cell viability was observed. We excluded FCS from the medium because it resulted in low transfections. The most suitable incubation time periods for in vitro DNA uptake and gene expression were 4 and $3 \mathrm{~h}$, respectively.

\subsection{DNA uptake and expression}

In this part of the study, we labelled polymers with fluorescein in order to follow uptake of the polymer by the cells. In addition, the plasmid DNA was labelled with SYBR-green I. Fig. $3 a$ and $b$ gives the representative micrographs of poly(NIPA)/PEI25L uptake to HeLa cells without plasmid DNA, and Fig. 3c and d shows DNA uptake with poly(NIPA)/ PEI25B/plasmid DNA which were taken with the light and fluorescence microscopes. The DNA uptake efficiencies obtained from these and other similar graphs are given in Fig. 4.

The important observations can be summarized as follows: The naked plasmid DNA molecules were not able to enter the cells as expected, while DNA uptake 

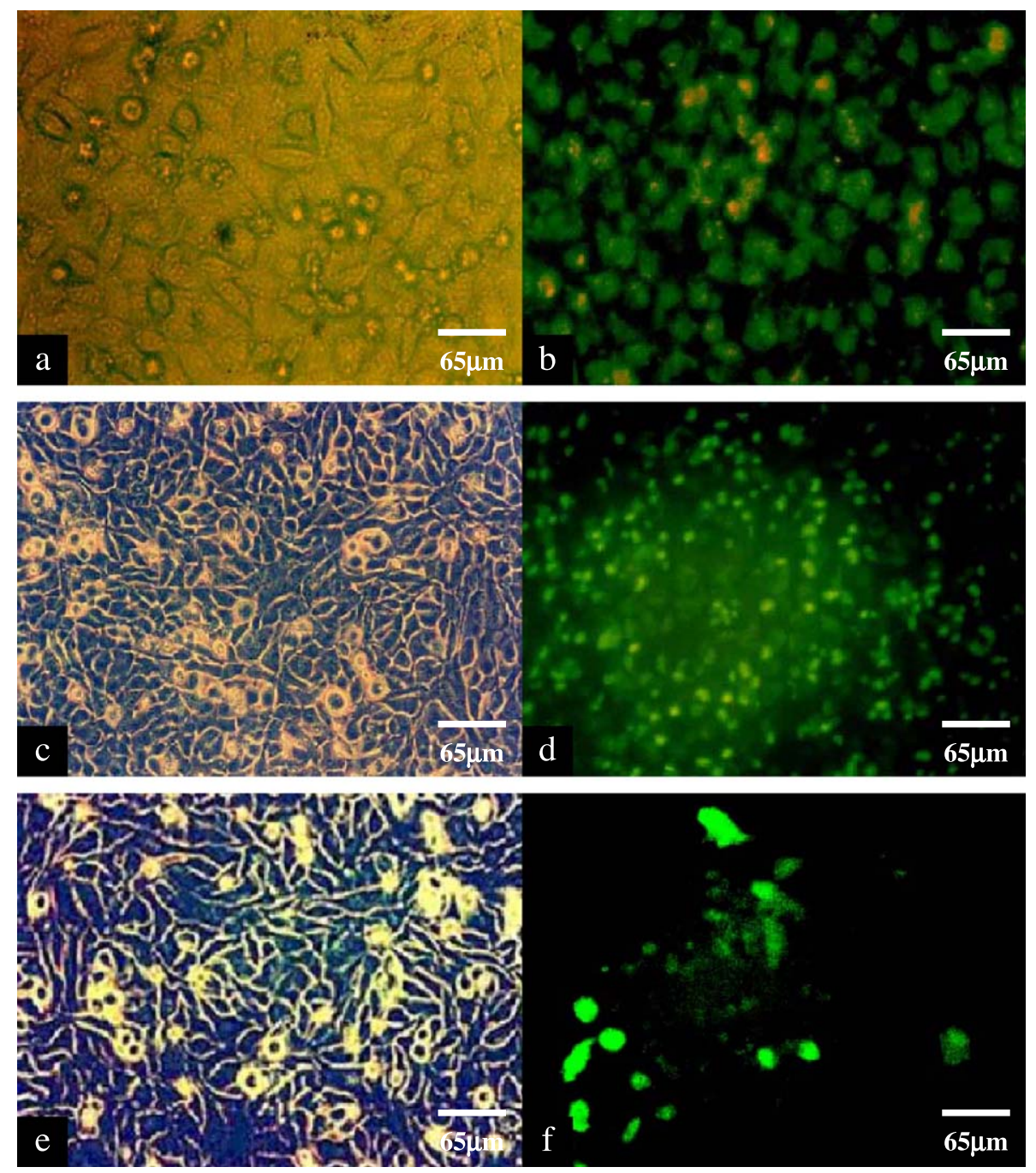

Fig. 3. Representative micrographs showing polymer and DNA uptake, and gene expression of HeLa cells in cell cultures: (a) Light microscopy image of poly(NIPA)/PEI25L uptake; (b) fluorescence microscopy image of poly(NIPA)/PEI25L uptake; (c) light microscopy image of DNA uptake with poly(NIPA)/PEI25B/plasmid DNA; (d) fluorescence microscopy image of DNA uptake with poly(NIPA)/PEI25B/plasmid DNA; (e) light microscopy image, gene expression, transfected with poly(NIPA)/PEI25L/plasmid DNA; (f) fluorescence microscopy image, gene expression, transfected with poly(NIPA)/PEI25L/plasmid DNA. All pictures were taken at $10 \times 20$ magnification. Plasmid DNA was labelled with SYBR-green I and polymer was labelled with fluorescein.

by the cells in the range of $5-70 \%$ were observed with polymer/plasmid complexes that we used. Note that both the type of the polymer and the polymer/ plasmid DNA ratio used in the preparation of the complexes significantly affected the uptake of the complexes by the cells. DNA uptake with PEI2B was low as expected (due to size and charge of the condensates). While DNA uptake with branched
PEI25B was quite high (about 60\%) and increased with polymer/plasmid DNA ratio up to 6. Interestingly, the uptake with the same molecular weight but linear PEI was low (as low as 10-20\%). Similarly, rather low DNA uptake was observed with the copolymer prepared with low molecular weight PEI (poly (NIPA)/PEI2B), however, even in that case DNA uptake efficiency reached about $20 \%$ when the copol- 


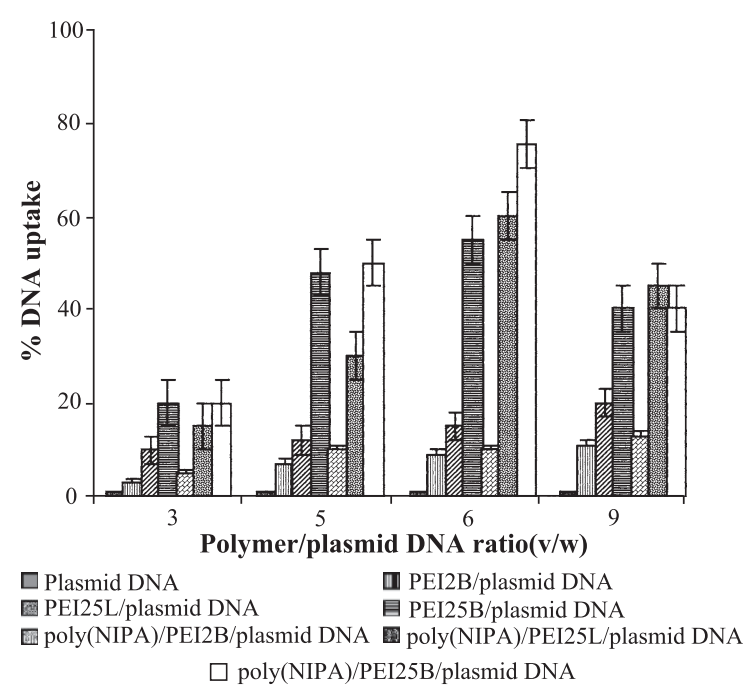

Fig. 4. Efficiency of DNA uptake of HeLa cells with naked plasmid DNA and its complexes with homo and copolymers.

ymer/ plasmid ratio was high (i.e., 9). Much higher DNA uptake values were reached with the complexes prepared with the copolymers with higher molecular weights $(25 \mathrm{kDa})$, especially when we used the branched PEI. The maximum uptake values for these two complexes were at the polymer/plasmid ratio of 6 . Further increase in this ratio reduced the transfection efficiencies.

All these can be explained by considering both the charge and size of the complexes (see Tables 3 and 4). For all polymers, the charge of the complexes increases when we increase the polymer/ plasmid ratio, which causes an increase in the DNA uptake efficiency. Even large complexes (even larger than $1000 \mathrm{~nm}$ ) can be uptaken by the cells due to the high positive charge. However, when we consider the complexes of copolymers, especially PEIs with 25-kDa molecular weight, we can observe the maximum DNA uptake efficiencies at a polymer/plasmid ratio of 6 . Notice that these complexes are significantly smaller than the others, which means that not only the charge but also the size of the complexes are important. Further increase in the polymer/plasmid DNA ratio cause a reduction in the DNA uptake efficiencies for these highly effective complexes (prepared with PEI25L and PEI25B). This may be due to the increase in the size (it is more difficult to uptake larger com- plexes). However, cytotoxicity due to high positive charge (see Fig. 2) may have also an additional negative effect.

From this part of the study, we can conclude that complexes prepared with copolymers (carrying PEI25L or PEI25B) are highly effective in DNA uptake to cells in vitro with high efficiencies. A positive charge around $10-14 \mathrm{mV}$ and complex size in the range of $200-300 \mathrm{~nm}$ seems optimal to reach high DNA uptake efficiencies. The complexes prepared with linear PEI25L are less effective than those prepared with the branched PEI25B. However, the later one exhibit higher cytotoxicity and therefore the linear one seems the best choice.

\subsection{Gene expression}

In the gene expression studies, no fluorescent label was used. Green fluorescent protein (GFP) expression in HeLa cells transfected in vitro cell cultures was followed both by light and fluorescent microscopy. Two representative micrographs are shown in Fig. 3e and $\mathrm{f}$, which clearly demonstrates gene expression.

Fig. 5 gives the GFP expression efficiencies of HeLa cells transfected with complexes of plasmid DNA and PEI homopolymers (PEI2B, PEI25L, PEI25B) and three different poly(NIPA)/PEI copolymers. The important results drawn from this figure can be summarized as follows: GFP expression efficien-

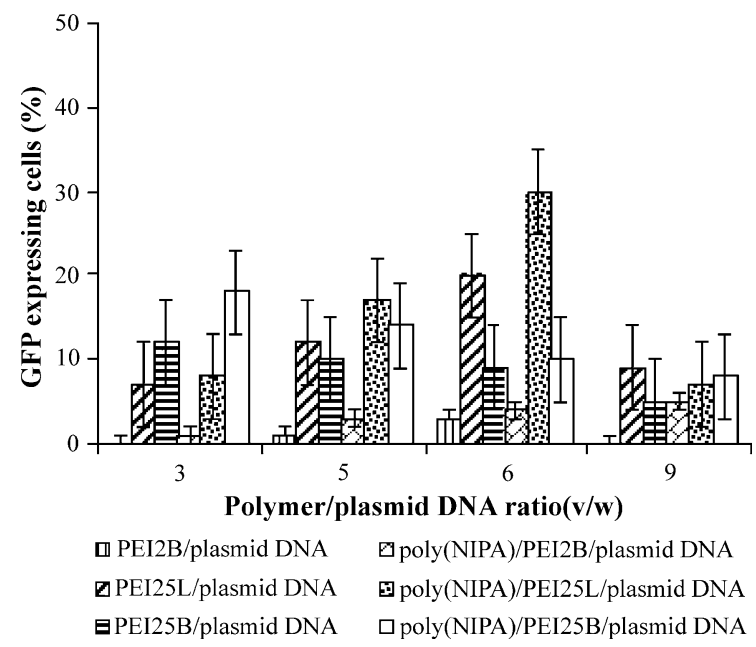

Fig. 5. GFP expression efficiency of HeLa cells transfected with complexes of plasmid DNA and PEI homopolymers and three different poly(NIPA)/PEI copolymers. 
cies were in the range of $5-35 \%$ with the polymer/ plasmid complexes that we used. Note that much higher DNA uptake efficiencies up to $70 \%$ were achieved with these complexes as discussed in the previous section. It means that the complexes can enter into the cells but the polymer and plasmid cannot be dissociated because of the tight interaction or plasmid may be degraded during endosomal escape and this causes a reduction in GFP expression.

Note that both the type of the polymer and the polymer/plasmid DNA ratio used in the preparation of the complexes significantly affected the GFP expression efficiency in parallel to DNA uptake efficiency except with PEI25B homopolymer. Although PEI25B showed quite high DNA uptake efficiency, its gene expression efficiency was around $10 \%$ most probably due to strong interaction of the polymer with plasmid DNA (low dissociation). Both uptake and transfection efficiency of the PEI2B homopolymer was low due to its size and charge. Gene expression efficiencies with linear PEI homopolymer (PEI25L) were lower than the DNA uptake efficiencies and increased with the polymer/plasmid ratio and reached a maximum at a ratio of 6. Rather low DNA uptake efficiencies were observed with the copolymer prepared with low molecular weight PEI (poly(NIPA)/PEI2B) in parallel to low DNA uptake efficiencies. The most successful gene expressions were achieved with the poly(NIPA)/ PEI25L and about 35\% expression (the maximum) was observed at a polymer/plasmid ratio of 6 . Note that this is almost half of the DNA uptake efficiency (around 60\%) observed with the same complex and with the same polymer/plasmid ratio. However, surprisingly gene expressions reached with the high molecular weight branched copolymer (PEI25B) was around $10 \%$, compared to the maximum DNA uptake value of about $70 \%$ (see Fig. 4) observed with the complexes prepared with this copolymer.

The reduction of gene expression may be expected. Because, as also mentioned in the related literature, the plasmid DNA complexes prepared with polycations can be uptaken by endocytosis within the cell, mainly due to the positive charge of these complexes. However, in order to express the target protein, first plasmid DNA must be released from the complex, and it would be available for RNA polymerase reading DNA information. It seems that complexes prepared with poly(NIPA)/PEI25L copolymer are the best poly- cation vectors that we have used in this study. They are even better than the complexes prepared with the same PEI25L homopolymer, which is the advantage of using the temperature sensitive copolymer that we proposed in this study, which most probably squeezes the plasmid and protects it from the environment. However, the copolymer of poly(NIPA) with the branched PEI (the same molecular weight, $25 \mathrm{kDa}$ ) does hold DNA very tightly, and, most probably does not release it effectively, which leads very low gene expression efficiencies. In addition, after entering into the cells very effectively (which means high DNA uptake efficiency) these complexes cause the death of some of the cells due to again a high positive charge.

In conclusion, we can say that complexes prepared with copolymers (carrying PEI25L not or PEI25B) are highly effective in DNA uptake by cells in vitro with high efficiencies. A positive charge around 10-14 $\mathrm{mV}$ and a complex size in the range of $200-300 \mathrm{~nm}$ seem optimal to reach high DNA uptake values. Although the gene expression is lower (compared to corresponding DNA uptake efficiencies), the complexes prepared with a poly(NIPA)/PEI25L copolymer with a polymer/plasmid ratio of 6 seems to be safe (low cytotoxicity) and therefore a quite satisfactory alternative polycationic non-viral vector system.

\section{Acknowledgements}

This project was supported by Hacettepe University, Scientific Affairs Division. Prof. Erhan Pişkin has supported by Turkish Academy of Sciences as a full member. This study was also supported by Hacettepe University (Project No: 020162004).

\section{References}

[1] O. Boussif, M.A. Zanta, J.P. Behr, Optimized galenics improve in vitro gene transfer with cationic molecules up to 1000-fold, Gene Ther. 3 (1996) 1074-1080.

[2] P. Erbacher, J.S. Remy, J.P. Behr, Gene transfer with synthetic virus-like particles via the integrin-mediated endocytosis pathway, Gene Ther. 6 (1999) 138-145.

[3] S. Han, R.I. Mahato, Y.K. Sung, S.W. Kim, Development of biomaterials for gene therapy, Molec. Ther. 2 (2000) 302-317.

[4] D. Finsinger, J.S. Remy, P. Erbacher, C. Koch, C. Plank, Protective copolymers for nonviral gene vectors: synthesis, 
vector characterization and application in gene delivery, Gene Ther. 7 (2000) 1183-1192.

[5] W.F. Anderson, Human gene therapy, Nature 392 (1998) $25-30$.

[6] I.M. Verna, N. Somia, Gene therapy-promises, problems and prospects, Nature 389 (1997) 239-242.

[7] Y.K. Song, F. Liu, D. Liu, Characterization of cationic liposome-mediated gene transfer in vivo by intravenous administration, Hum. Gene Ther. 8 (1997) 1585-1594.

[8] B. Abdallah, L. Sachs, B.A. Demeneix, Non-viral gene transfer: application in developmental biology and gene therapy, Biol. Cell 85 (1995) 1-7.

[9] X. Gao, L. Huang, Cationic liposome-mediated gene transfer, Gene Ther. 2 (1995) 710-722.

[10] G. Gregoriadis, R. Saffie, J.B. De Souza, Liposome-mediated DNA vaccination, FEBS Lett. 402 (1997) 107-110.

[11] J.S. Remy, C. Sirlin, P. Vierling, J.P. Behr, Gene transfer with a series of lipophilic DNA-binding molecules, Bioconjug. Chem. 5 (1994) 647-654.

[12] M.C. Filion, N.C. Philips, Major limitations in the use of cationic liposomes for DNA delivery, Int. J. Pharm. 162 (1998) 159-170.

[13] O. Boussif, H.F. Lezoualc, M. Zanto, M. Mergny, D. Scherman, B.A. Demeneix, J.P. Behr, A versatile vector for gene and oligonucleotide transfer into cells in culture and in vivo: polyethylenimine, Proc. Natl. Acad. Sci. U. S. A. 92 (1995) 7031-7297.

[14] P.L. Felgner, T.R. Holm, R. Roman, H.W. Chan, M. Wenz, J.P. Northrop, G.M. Ringold, M. Danielsen, Lipofection - a highly efficient, lipid-mediated DNA-transfection procedure, Proc. Natl. Acad. Sci. U. S. A. 84 (1987) 7413-7417.

[15] K.A. Mislick, J.D. Baldeschwieler, J.F. Kayyem, T.J. Meade, Transfection of folate-polylysine DNA complexes: evidence for lysosomal delivery, Bioconjug. Chem. 6 (1995) 512-515.

[16] A. Kichler, C. Leborgne, E. Coeytaux, O. Danos, Polyethylenimine-mediated gene delivery: a mechanistic study, J. Gene Med. 3 (2001) 135-144.

[17] W.T. Godbey, K.K. Wu, A.G. Mikos, Poly(ethylenimine)-mediated gene delivery affects endothelial cell function and viability, Biomaterials 22 (2001) 471-480.

[18] J.M. Benns, A. Maheshwari, D.Y. Furgeson, R.I. Mahato, S.W. Kim, Folate-PEG-Folate-graft-polyethyleneimine-based gene delivery, J. Drug Target. 9 (2003) 123.

[19] J.P. Behr, The proton sponge: a means to enter cells viruses never thought of, Med. Sci. 12 (1996) 56-58.

[20] M. Yokoyama, Gene delivery using temperature responsive polymeric carriers, Drug Discov. Today 7 (2002) 426-432.

[21] W.T. Godbey, K.K. Wu, G.J. Hirasaki, A.G. Mikos, Improved packing of poly(ethyleneimine)/DNA complexes increases transfection efficiency, Gene Ther. 6 (1999) 1380-1388.

[22] J.L. Coll, P. Chollet, E. Brambilla, D. Desplanques, J.P. Behr, M. Farvot, In vivo delivery to tumors of DNA complexed with linear polyethylenimine, Hum. Gene Ther. 10 (1999) $1659-1666$.

[23] W.T. Godbey, K.K. Wu, A.G. Mikos, Size matters: molecular weight affects the efficiency of poly(ethylenimine) as a gene delivery vehicle, J. Biomed. Mater. Res. 45 (1999) 268-275.
[24] P. Stayton, T. Shimoboji, C. Long, A. Chilkoti, G. Chen, J.M. Harris, A.S. Hoffman, Control of protein-ligand recognition using a stimuli-responsive polymer, Nature 378 (1995) $472-474$

[25] V. Bulmus, S. Patır, A. Tuncel, E. Piskin, Stimuli-responsive properties of complexes of poly $(N$-isopropylacrylamide-coacrylic acid) with alanine, glycine and serine mono-, di-, and tri-peptides, J. Control. Release 76 (2001) 265-274.

[26] W.L. Hinrich, N.M.E. Schuurmans-Nieuwenbroek, P. van der Wetering, W.E. Hennink, Thermosensitive polymers as carriers for DNA delivery, J. Control. Release 60 (1999) 249-259.

[27] M. Kurisawa, M. Yokoyama, T. Okano, Transfection efficiency increases by incorporating hydrophobic monomer units into polymeric gene carriers, J. Control. Release 68 (2000) $1-8$.

[28] T. Nagasaki, Synthesis of a novel water-soluble polyazobenzene dendrimer and photoregulation of affinity toward DNA, Mol. Cryst. Liq. Cryst. 345 (2000) 227-232.

[29] S. Dinçer, A. Tuncel, E. Piskin, A potential gene delivery vector: $N$-isopropylacryl amide-ethyleneimine block copolymers, Macromol. Chem. Phys. 203 (2002) 1460-1465.

[30] F. Ganachaud, M.J. Monterio, R.G. Gilbert, M.-A. Dourges, S.H. Thang, E. Rizzardo, Molecular weight characterization of poly( $N$-isopropylacrylamide) prepared by living free-radical polymerization, Macromolecules 33 (2000) 6738-6745.

[31] C. Bouitris, E.G. Chatzi, C. Kiparissides, Characterization of the LCST behaviour of aqueous poly( $N$-isopropylacrylamide) solutions by thermal and cloud point techniques, Polymer 38 (1997) 2567-2570.

[32] J.S. Remy, B. Abdallah, M.A. Zanta, O. Boussif, J.P. Behr, B. Demeneix, Gene transfer with lipospermines and polyethylenimine, Adv. Drug Deliv. Rev. 30 (1998) 85-95.

[33] R. Kirchler, L. Wightman, E. Wagner, Design and gene delivery activity of modified polyethylenimines, Adv. Drug Deliv. Rev. 53 (2001) 341-358.

[34] P. Erbacher, J.P. Behr, J.S. Remy, Transfection and physical properties of various saccharide, poly(ethyleneglycol), and antibody derivatized polyethylenimines (PEI), J. Gene Med. 1 (1999) 210-222.

[35] C.H. Ahn, S.Y. Chae, Y.H. Bae, S.W. Kim, Biodegradable poly(ethylenimine) for plasmid DNA delivery, J. Control. Release 80 (2002) 273-282.

[36] M.X. Tang, F.C. Szoka, The influence of polymer structure on the interaction of cationic polymers with DNA and morphology of the resulting complexes, Gene Ther. 4 (1997) $823-832$.

[37] M. Ogris, P. Steinlein, M. Kursa, K. Mechtler, R. Kircheis, E. Wagner, The size of DNA/transferrin-PEI complexes is an important factor for gene expression in cultured cells, Gene Ther. 5 (1998) 1425-1433.

[38] D.D. Dunlap, A. Maggi, M.R. Soria, L. Monaco, Nanoscopic structure of DNA condensed for gene delivery, Nucleic Acids Res. 25 (1997) 3095-3101.

[39] L. Wigman, E. Patzelt, E. Wagner, R. Kircheis, Development of transferrin-polycation/ DNA based vectors for gene delivery to melanoma cells, J. Drug Target. 7 (1997) 293-303.

[40] J.H. Jeong, S.H. Song, D.W. Lim, H. Lee, T.G. Park, DNA 
transfection using linear poly(ethylenimine) prepared by controlled acid hydrolysis of poly(2-ethyl-2-oxazoline), J. Control. Release 73 (2001) 391-399.

[41] D. Fischer, R. Zange, T. Kissel, Comparative in vitro cytotoxicity studies of polycation for gene therapy, Int. Symp. Control. Release Bioact. Mater. 24 (1997) 527-528.

[42] D. Fischer, T. Bieber, H.P. Elasser, T. Kissel, Polyethylenimine; synthesis and in vitro cytotoxicity of a low molecular weight polycation for gene transfer, Eur. J. Cell Biol. 75 (1998) 108-116.

[43] D. Fischer, T. Bieber, Y. Li, H.P. Elsasser, T. Kissel, A novel non-viral vector for DNA delivery based on low molecular weight, branched polyethleneimine: effect of molecular weight on transfection efficiency and cytotoxicity, Pharm. Res. 16 (1999) 1273-1279.

[44] S. Choksakulnimitr, S. Masuda, H. Tokuda, Y. Takakura, M. Hashida, In vitro cytotoxicity of macromolecules in different cell culture systems, J. Control. Release 34 (1995) $233-241$.

[45] L. Wightman, R. Kircheis, V. Rössler, S. Carotta, R. Ruzicka, M. Kursa, E. Wagner, Different behavior of branched and linear polyethylenimine for gene delivery to mouse brain, J. Gene Med. 3 (2001) 362-372.

[46] G.F. Lemkine, D. Goula, N. Becker, G. Levi, B.A. Demeneix, Optimization of polyethylenimine-based gene delivery to mouse brain, J. Drug Target. 7 (1999) 305-312. 